\title{
Intra-abdominal dilation of artificial bowel sphincter pressure-regulating balloon: a case report
}

\author{
Bartholomeus van Wunnik • Walter Mastboom • \\ Steffan Rödel • Cornelius Baeten
}

Accepted: 1 February 2011 /Published online: 2 March 2011

(C) The Author(s) 2011. This article is published with open access at Springerlink.com

\begin{abstract}
Introduction Fecal incontinence is a debilitating condition with considerable impact on quality of life. The artificial bowel sphincter may be used as a treatment option in severe cases in which no less invasive form of therapy is sufficient.

Results Risk of infection and mechanical failure is of particular concern in this artificial device.

Conclusion We report a rare late complication: balloon dilation due to hypertonic fillings.
\end{abstract}

Keywords Artificial bowel sphincter Complications

Fecal incontinence is a socially disabling condition for which several surgical treatments are available [1]. The artificial bowel sphincter (ABS; Acticon, American Medical Systems, Minnetonka, MN) (Fig. 1) is a well-publicized treatment option for severe intractable fecal incontinence which offers the patient a chance for continence restoration and improved quality of life [2-5]. We report an unusual late complication of this procedure.

As the implantation procedure has been described extensively elsewhere, we will only briefly summarize the technique [3]. The ABS system consists of three parts: cuff,

B. van Wunnik $\cdot$ C. Baeten $(\square)$

Department of Surgery, Maastricht University Medical Centre,

Postal Box 5800, 6202 AZ Maastricht, The Netherlands

e-mail: c.baeten@mumc.nl

W. Mastboom $\cdot$ S. Rödel

Department of Surgery, Medisch Spectrum Twente,

Enschede, The Netherlands pump, and pressure-regulating balloon. The cuff is placed around the anal canal by blunt dissection using two lateral incisions. The pump is implanted in the labia majora or scrotum. The pressure-regulating balloon is placed through a transverse, suprapubic incision to accommodate insertion. The rectus abdominis muscles are retracted to expose the space of Retzius where the balloon is implanted.

The pressure-regulating balloon controls the amount of pressure exerted on the anal canal by the occlusive cuff. It is made of silicone elastomer and is provided in three pressure ranges (81-90 cm $\mathrm{H}_{2} \mathrm{O}$; 91-100 $\mathrm{cm} \mathrm{H}_{2} \mathrm{O} ; 101-110 \mathrm{~cm} \mathrm{H}_{2} \mathrm{O}$ ). In this case a $91-100 \mathrm{~cm} \mathrm{H}_{2} \mathrm{O}$ balloon had been implanted.

The Acticon neosphincter is filled with contrast solutions or normal saline. The solution must be sterile and isotonic to minimize the transfer of fluid across the silicone membrane, which is semipermeable. Contrast media diluted with sterile water are used as a filling solution to improve imaging of the device. The presence of particles in the filling solution can affect the operation of the pump.

A now 30-year-old male received an ABS to control continence in 2001 after a severe pelvic trauma with a rupture of the sphincter complex in 1999. This patient was evaluated for an unknown progressive swelling in his abdomen as well as urinary and defecation difficulties at the emergency department at Medisch Spectrum Twente in June 2009. The swelling was noticed several months earlier but discarded by the patient as related to his trauma surgery or starting adipositas.

Physical examination showed no abnormal findings other than a palpable swelling in the lower abdomen of approximately $15 \mathrm{~cm}$. Abdominal ultrasound showed a cystic lesion in the lower abdomen with debris of an unknown origin. A computed tomography (CT) scan (Fig. 2) revealed a large cystic swelling in the lower pelvic 


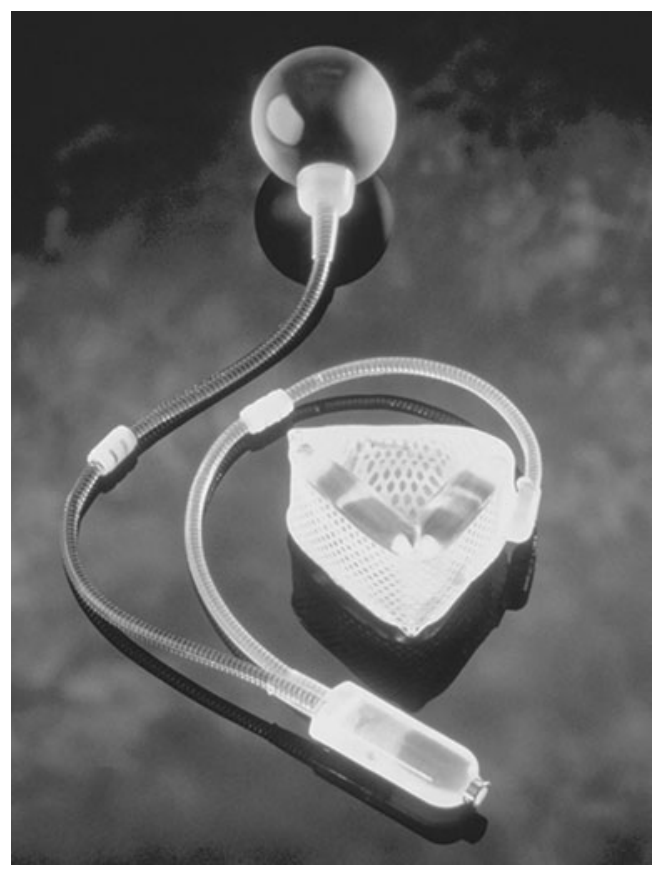

Fig. 1 The artificial bowel sphincter

area with an open connection to the tubing of the ABS system. The CT scan also showed a stretched rectus abdominis muscle overlying the reservoir indicating a normal position of the balloon. The process was therefore attributed to an abnormal swelling of the pressureregulating balloon. Based on the CT scan, a volume of approximately $1,400 \mathrm{cc}$ was measured as opposed to a normal volume of $43 \mathrm{cc}$.

Patient underwent surgery to remove the balloon by median laparotomy (Figs. 3 and 4). The balloon was explanted and the remaining system was closed and left in situ with the aim to replace the balloon in a second stage. Thereafter, a double-barreled colostomy was performed.

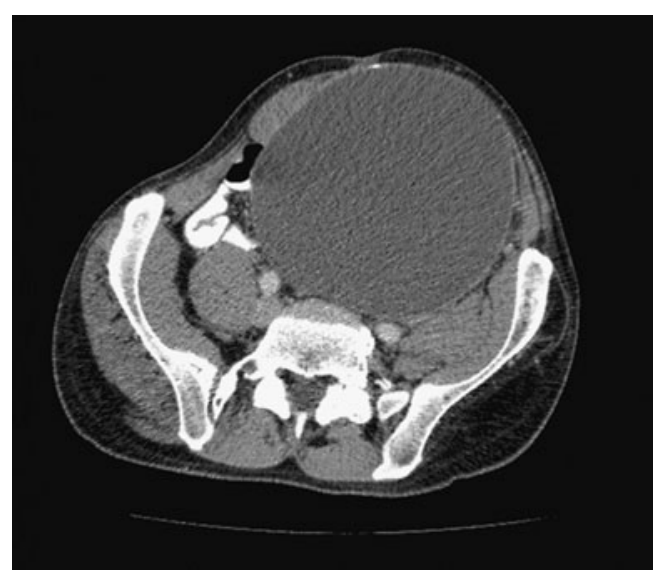

Fig. 2 CT scan revealed a large cystic swelling in the lower pelvic area

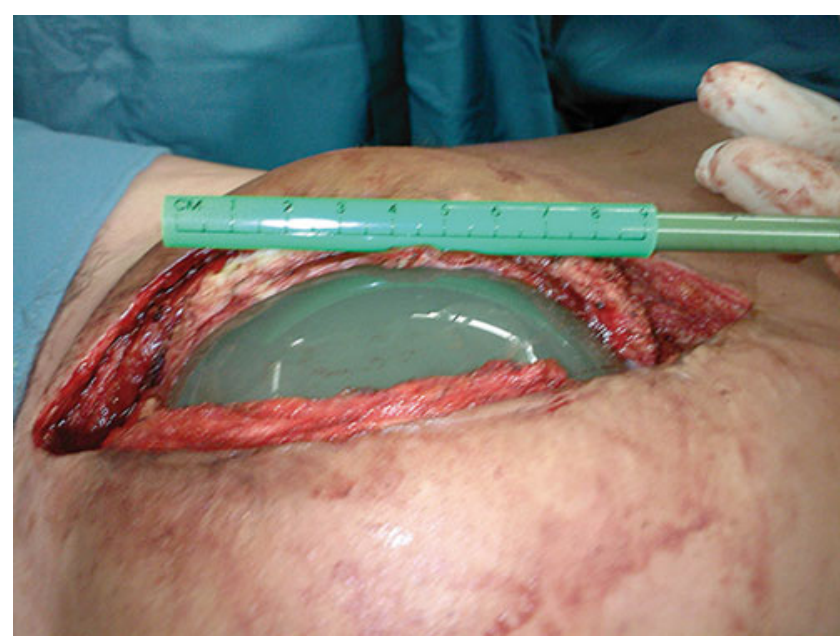

Fig. 3 Balloon removal by median laparotomy

Clear fluid from the balloon was collected for analysis. The patient recovered without signs of infection and was eligible for implantation of a new pressure-regulating balloon. During this second procedure at Maastricht University Medical Centre, fluid was recovered from the remaining system and preserved for analysis. As this fluid was dark and cloudy and therefore suspected to be contaminated the cuff and tubing were explanted as well and replaced with a new ABS. The contrast solution (Omnipaque $240 \mathrm{mgI} / \mathrm{ml}$, Nycomed with sterile water) used to fill the new balloon was also preserved and sent for analysis. The patient recovered without any problems and the ABS was activated at the outpatient clinic 1 month later.

Analysis of the fluid retrieved from the dilated balloon showed an osmolality of 297 milliosmoles per kilogram $(\mathrm{mOsm} / \mathrm{kg})$ and a density of $1.00 \mathrm{~g}$ per milliliter $(\mathrm{g} / \mathrm{ml})$. Fluid retrieved from the remaining system showed an osmolality of $306 \mathrm{mOsm} / \mathrm{kg}$ and a density of $0.99 \mathrm{~g} / \mathrm{ml}$.

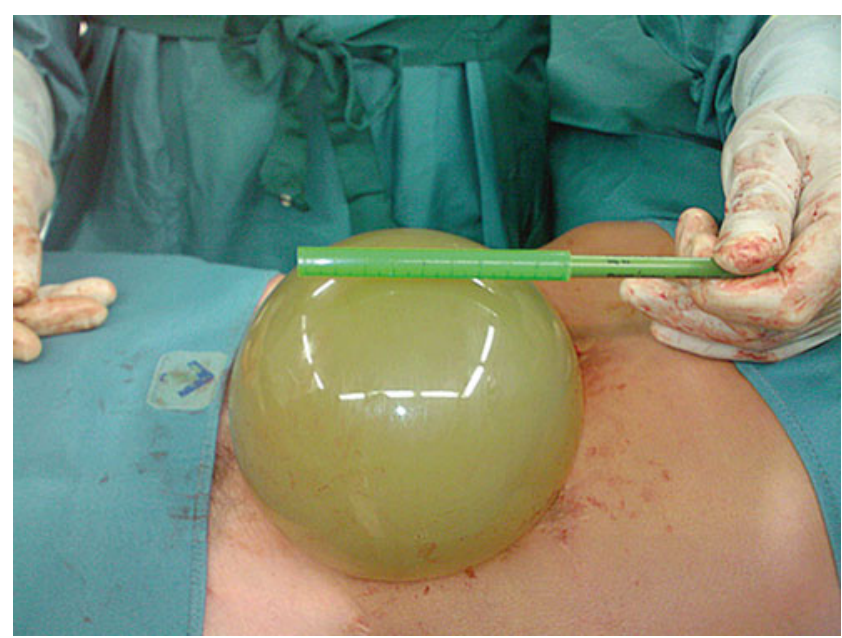

Fig. 4 Balloon removal by median laparotomy 
Normal human reference range of osmolality in plasma is about $275-299 \mathrm{mOsm} / \mathrm{kg}$. Normal human blood density is approximately $1.06 \mathrm{~g} / \mathrm{ml}$. The test results from the collected fluid are isotonic. The contrast solution however showed an osmolality of $337 \mathrm{mOsm} / \mathrm{kg}$ and a density of $1.15 \mathrm{~g} / \mathrm{ml}$. This is a hypertonic fluid despite being the exact solution as recommended by the manufacturer.

The osmotic pressure gradient across the semipermeable balloon is opposed by the tension of the balloon creating an equilibrium. We speculate that the fluid inside the balloon had reached equilibrium with the surrounding tissues before explantation. This was confirmed by analysis of the osmolality. An explanation for the late stage increase in size of the balloon may be balloon fatigue and stretching of the pores (the pressure is inversely proportional to the radius of the balloon) allowing for a larger inflow of particles including proteins establishing equilibrium relatively quickly and with a much larger total volume. This was confirmed after analysis of ion and protein content which was similar to plasma values according to blood tests prior to surgery with the exception of total amount of protein. This was still lower than the plasma value and probably a result of particle size.

No other insights have been provided by the manufacturer American Medical Systems after consultation with their engineers.

Since the introduction of the neosphincter, the use of ABS has been limited because of a high complication rate. Common problems with the system are mechanical failure, perineal erosion, and infection of which the latter occurs most frequent. A systematic review by Mundy et al. concludes the ABS to be of uncertain benefit and to possibly be harmful for patients. Infection was reported in 12 out of 14 studies included averaging $22.5 \%$ and erosion in $17.4 \%$. Surgical revision was reported in 13 out of 14 studies included averaging 42.6\%. Carmona et al. also found a high rate of morbidity $(100 \%, 1$ infection, 5 erosions and 19 further surgeries in 17 patients) but conclude that in patients without complications, the ABS produces considerable results. A case series published by Melenhorst et al. showed 7 (21.2\%) infections and 26 further surgeries in 33 patients. Stringent patient selection as well as patient information is strongly recommended $[6,7]$.

Prior to this report, no mechanical failure on the basis of hypertonic balloon contrast fluids has been reported.

Surgeons implanting the ABS as a neosphincter need to be aware of the possibility of balloon dilation due to hypertonic fillings next to other complications arising with its use.

Open Access This article is distributed under the terms of the Creative Commons Attribution Noncommercial License which permits any noncommercial use, distribution, and reproduction in any medium, provided the original author(s) and source are credited.

\section{References}

1. Muller C, Belyaev O, Deska T, Chromik A, Weyhe D, Uhl W (2005) Fecal incontinence: an up-to-date critical overview of surgical treatment options. Langenbecks Arch Surg/Deutsche Gesellschaft fur Chirurgie 390(6):544-552

2. Christiansen J, Lorentzen M (1987) Implantation of artificial sphincter for anal incontinence. Lancet 2(8553):244-245

3. Wong WD, Congliosi SM, Spencer MP, Corman ML, Tan P, Opelka FG, Burnstein M, Nogueras JJ, Bailey HR, Devesa JM, Fry RD, Cagir B, Birnbaum E, Fleshman JW, Lawrence MA, Buie WD, Heine J, Edelstein PS, Gregorcyk S, Lehur PA, Michot F, Phang PT, Schoetz DJ, Potenti F, Tsai JY (2002) The safety and efficacy of the artificial bowel sphincter for fecal incontinence: results from a multicenter cohort study. Dis Colon Rectum 45(9):1139-1153

4. Lehur PA, Zerbib F, Neunlist M, Glemain P, Bruley des Varannes S (2002) Comparison of quality of life and anorectal function after artificial sphincter implantation. Dis Colon Rectum 45(4):508-513

5. Melenhorst J, Koch SM, van Gemert WG, Baeten CG (2008) The artificial bowel sphincter for faecal incontinence: a single centre study. Int J Colorectal Dis 23(1):107-111

6. Mundy L, Merlin TL, Maddern GJ, Hiller JE (2004) Systematic review of safety and effectiveness of an artificial bowel sphincter for faecal incontinence. Br J Surg 91(6):665-672

7. Carmona R, Company RA, Vila JR, Bueno AS, Marti P (2008) Long-term results of artificial bowel sphincter for the treatment of severe fecal incontinence. Are they what we hoped? Colorectal Dis 11(8):831-7 